\title{
Baudrillard el incierto ${ }^{1}$
}

\author{
Javier Callejo
}

UNED

La pataphysique est la science des solutions imaginaires, qui accorde symboliquement aux linéaments les proprietés des objects décrits par leur virtualité

(Alfred Jarry, Livre II, chapitre VIII, Gestes et opinions du docteur Faustroll, pathaphysicien)

Como bien es sabido, el inmortal Borges no era muy dado a hablar de política. Puede decirse, con sus propias palabras, que, sobre tal asunto, era aprensivo a la manera de los porteños (La intrusa). Pero las sendas ventanas que construyó a partir de las dos narraciones protagonizadas por un personaje al que denomina Baudrillard, le permitieron fijar su particular sistema político, seguramente con la intención de que nadie más le volviese a preguntar sobre él.

He de empezar apuntando lo extraño que son los personajes franceses en la narrativa borgiana. Prefería a argentinos, chilenos, orientales e ingleses, siendo varios de estos últimos los que tomaron sus imposturas, pasándolas por Kipling. Para Borges (El idolatrado hombre muerto), los franceses -especialmente los parisinos- tenían inteligencia y gracia; pero eran cualidades que alimentaban la pedantería y el rencor. Quizá por ello y a pesar del carácter francés del personaje, nos deja algunas dudas sobre su origen. La interpretación que parece más pertinente es la de que se trata de alguien nacido en el país galo; pero que

\footnotetext{
${ }^{1}$ Texto de la intervención en un homenaje a Jean Baudrillard celebrado en la librería Enclave, de Madrid, en el 13 de febrero de 2020.
} 
queda fascinado por América, como una especie de segundo Tocqueville encargado de actualizar La democracia en América en una La sociedad en América. La interpretación alternativa es la que tiene que, aun con antecedentes inmediatos en Francia, Baudrillard realmente nace en América y hace un esfuerzo reflexivo, como agradecimiento y reconocimiento a sus antepasados, en forma de descriptivo cuento de su experiencia como recién norteamericano. Un esfuerzo en clave de advertencia, de descripción de lo que les espera.

En el primero de los textos, titulado Jean Baudrillard no ha tenido lugar, desentrañó desde su elegante distancia expositiva, casi analítica, lo que puede concebirse como toda una teoría de la sociedad y la política. Para ello, diseñó al protagonista como sociólogo. Aun cuando como un sociólogo muy particular. Tal vez el más literario de los sociólogos. De aquí que, como en otras narraciones del propio Borges, el autor traza las peripecias del autor referido, del personaje, a través de los documentos de los que deja huella. Así, los libros que atribuye a Baudrillard toman la forma de escenas.

El núcleo de la narración es trágico y toma como referencia la tragedia del doble de El estudiante de Praga, invocada varias veces por el protagonista. Es la carcajada trágica del que sabe que es irrecuperable el alma vendida al diablo. Es la risa profunda de quien concibe una sociedad -una civilización- que ha vendido el alma -lo social- al diablo. Lo social no es el mal; pero es donde se sitúa el mal. Un mal hecho transparente.

En la obra de Baudrillard, que es el espejo a partir del cual se dibujan los perfiles del personaje, la Modernidad es esa civilización en busca de su doble, de sus dobleces, para el imposible intento de recuperarlo, convirtiéndose ella misma en el doble de sus dobleces. Modernidad que busca su doble en las sociedades primitivas y que, por eso, las encierra en museos. Y, así, encierra lo social (perdido) que supuestamente busca en las sociedades primitivas.

La Modernidad busca su doble en las sociedades del futuro... y produce ciencia ficción a la que intentará parecerse, como se intenta parecer a 1984, de Orwell; a Un mundo feliz, de Huxley; o a Blade Runner, más de Ridley Scott, que de Philip K. Dick (¿Sueñan los androides con ovejas eléctricas?). La sociedad (moderna) intenta parecerse a sus dobles, como ocurre con los resultados que arrojan las encuestas. Interesantes no porque digan cómo es la sociedad, sino porque apuntan cómo quiere ser la sociedad. Fragmentos en los que se dibuja un sociólogo reflexivo con la ambición de abrazar los instantes más significativos de lo que certifica como presente. 
Se habrán dado cuenta de la división entre lo social y la sociedad. Creo que es central; pero apenas tenemos tiempo y espacio aquí para entrar en ella. Atraviesa toda la teoría sociológica. Quedémonos, perfilando la oposición, con que la sociedad es el mundo de los significantes, de la distinción, de los estilos de vida; mientras que lo social es el de lo que va y dejar irse, casi de lo insignificante, el de lo intranscendente, el de la reciprocidad. Lo que une a la gente entre sí (Crimen perfecto). Por definición, lo social está excluido de la sociedad. Lo que entra en la sociedad es una reproducción simbólica legitimada de lo social. Lo social es lo que carece de identidad. Señalado, despectivamente, como la masa. En la sombra de las mayorías silenciosas, situadas en la sociedad, está la masa, lo social. Las masas no tienen historia, significado, conciencia o deseo. Las masas son el potencial residuo de toda historia, significado y deseo (The illusion of the end). Son expulsadas de toda estrategia societaria y política por su incapacidad de entenderla (The illusion of the end). Frente a la trascendente sociedad, la masa de lo social es inmanente.

Pues bien, el sociólogo Baudrillard esculpe una sociedad que ha vendido lo social y, de ahí, el exceso de realidad en los discursos. Como lo ha vendido, está en todas partes, como las monedas de menor valor. Como nuestros céntimos de euro, que están por todas partes, menos cuando son necesitados, como cuando queremos obtener el ticket del aparcamiento callejero. Lo social-real se encuentra abolido por su elevación a la potencia de modelo, se hace decir de manera retadora a nuestro personaje ( $A$ L'ombre des majorités silencieuses). Lo social es un virus que solo se manifiesta cuando el metabolismo de la sociedad se encuentra débil y las defensas, que le hacen inmune, se encuentran bajas.

Lo real-social está especialmente en los discursos de la política. Hay un denodado esfuerzo por presentar víctimas, que son aquellos elegidos de encarnar la realidad de lo social (Crimen perfecto). Nuestro mayor esfuerzo simbólico se encuentra en la representación de esta realidad de lo social. La política se afana especialmente en representarla: los descamisados, los desahuciados, los desterrados, los refugiados de conflictos bélicos y las víctimas del terrorismo, como las mayores víctimas de todas las víctimas, porque son etiquetadas como nuestras víctimas.

La política imagina lo real y lo convierte en realidad virtual, en apariencia. Como dice otro personaje borgiano, Zizek: la indignación es una apariencia. La implosión indignada de la masa es convertida en apariencia. La realidad de la política es un modelo de lo real, que permite la supervivencia de la política. Cuando los políticos caen en las promesas son siempre falaces, y como dice el 
personaje Baudrillard, son eficaces porque son falaces ( $A$ L'ombre des majorités silencieuses), porque sus promesas quedan pegadas a la pantalla. A las pantallas que tanto le gustan a Baudrilllard, pues, al fin y al cabo, las posibilidades del mundo se reducen a lo que puede verse en una pantalla. Un mundo más real que el real: hiperreal. Una sociedad a punto de enterrar lo social bajo las simulaciones de lo social. Lo de "a punto" deja al lector con la casi certeza de que lo social volverá, aunque sea como zombi.

Los medios de comunicación, a los que se acusa muy alegremente de tener como única función la del entretenimiento, son las principales fuentes suministradoras de imágenes de la realidad de lo social. Las pantallas de televisión, las redes sociales, los foros en internet, nos hacen una despiadada transcripción de lo realsocial, en tiempo real (Crimen perfecto). Exceso de lo real: hiperrealismo. Cuanta mayor transparencia de lo real-social, mayor apariencia. La desnudez de lo realsocial es síntoma de su ocultación. Se oculta lo real-social por su muestra continua. Incluso cuando no hay material significante para mostrarlo. Borges insiste en esta obsesión de Baudrillard y describe prolijamente el ufano gesto del sociólogo francés diciendo: la guerra (de Irak) no ha sido porque no ha tenido imágenes del campo de batalla, no ha tenido ni su simulacro.

El personaje se vuelve provocador. Casi hasta la agresión de la conciencia bienpensante de esa contradictoria y paradójica masa de progresistas de izquierda, que eran quienes le seguían hasta el paroxismo. El personaje enfrentado a sus seguidores en una actitud que podría entenderse como suicida. Pero nada más lejos. El momento que describe Borges es el del personaje que se siente poderoso. Muy poderoso a partir de sus dotes para el argumento y la convicción. Tan poderoso que acepta el reto de retorcer las entrañas de las conciencias de sus seguidores.

Tal vez sea conveniente traer aquí un fragmento del carácter provocativo que adquiere el personaje:

Uno de los caracteres a menudo citados de la opresión de las mujeres es la expoliación del goce, su carencia de goce. Flarante injusticia que todos tienen que intentar reparar inmediatamente, según el esquema de una especie de carrera de fondo o de rallye sexual. El goce ha tomado el aspecto de una exigencia y de un derecho fundamental. Benjamín de los derechos del hombre, ha accedido a la dignidad de un imperativo categórico. Es inmoral contravenirlo. Pero no tiene siquiera el encanto kantiano de las finalidades sin fin. Se impone como gestión y autogestión del deseo, y su ignorancia no excusa su cumplimiento, como ocurre con la ley. 


\begin{abstract}
Es ignorar que el goce también es reversible, es decir, que puede tener una intensidad superior en su ausencia o su negación. Por lo mismo cuando el fin sexual vuelve a ser aleatorio, surge algo que puede llamarse seducción o placer. O más todavía, el goce puede no ser más que el pretexto de otro juego más apasionante, más pasional ( $D e$ la seducción, p.24).
\end{abstract}

Discurso en el que Borges parece adaptar al estilo postmodernista la escena del discurso de Marco Antonio/Marlon Brando en Julio César de Shakespeare/Mankiewicz. Escena de gran influencia en Borges, como reconoció en sus ahora olvidadas Memorias.

Muchos de sus anteriores seguidores no aguantaron tales discursos. Demasiado ambiguos para sus rígidos dogmas de cartilla prescriptiva del buen progre. Se negaron a volver a leer cualquier nuevo libro de este autor. Es más, ni siquiera se atrevieron a volver a leer los libros que habían adquirido, años antes, con devoción. Quedaron repartidos entre las cajas de mudanzas que nunca se abren, las segundas y terceras filas en las baldas de libros o en los trasteros. Como una pesadilla.

Baudrillard se muestra como el coherente y muestra la coherencia del mundo que ve. Es una coherencia que reta. Un libro seductor sobre la seducción. Cima de su coherencia en la incertidumbre. La guerra sin imágenes es el crimen perfecto de la realidad de lo social, que ya había anunciado Baudrillard en preclaras obras anteriores, como $A$ la sombra de las mayorías silenciosas y, sobre todo, El crimen perfecto. Con la muerte de lo social, desaparece la ilusión de la revolución. No la revolución sino la ilusión de la revolución. Lo que nos define como civilización -y por eso creo que Borges publica este cuento- es la ausencia. La ilusión de la ausencia.

Más acá de la guerra, la televisión nos facilita nuestra dosis de lo social-real. Poniéndolo en la pantalla, como si hubiera un "otro lado de la pantalla", nos protege de nuestra insoportable responsabilidad (The illusion of the end).

Si hay algo que atraviesa la obra de Baudrillard, es la ausencia. Es una literatura de la ausencia. Así nuestro personaje dice: "La ausencia de las cosas por sí mismas, el hecho de que no se produzcan a pesar de lo que parezca, el hecho de que todo se esconda detrás de su propia apariencia y que, por tanto, no sea jamás idéntico a sí mismo, es la ilusión material del mundo" (Crimen perfecto, p. 13). 
Es la ausencia de todo, o casi todo. Es la ausencia de crítica en la crítica social. Obligada a sobrevivir, también presenta simulacros de lo real-social, pues, al fin y al cabo es su objeto (Crimen perfecto). En Jean Baudrillard no ha tenido lugar, lo real-social es solo un mensaje, programa o serie de alta definición. Es un mensaje para la sociedad. Es, invirtiendo a Mandeville, la "virtud pública" (señalar lo real-social), que tiene como consecuencia (no querida, por supuesto), la supervivencia de una crítica fácil, ramplona, sin imaginación, de líder de la globalización azuzando contra el mal absoluto en forma de neoliberalismo.

Instalado en la ausencia, es el vacío el núcleo del texto de Baudrillard central en el decenio de los noventa -La ilusión del fin- en el que se enfrenta al efecto 2000 y, habría que decir, a todos los efectos del dominio de la economía política del signo. Deberíamos preguntarnos qué significa políticamente ese vacío. ¿Es el fin de la historia?, ¿es el fin de la linealidad de la historia?, ¿es el fin del progreso? A lo sumo, es la acelerada curva de la vuelta atrás. Es la ilusión de todos esos fines. Lo importante es el concepto de fin. Estamos en una cultura del final. Vivimos en el final continuo de una historia interminable (The illusion of the end). Pero nuestro apocalipsis no es real, es virtual. Y no está en el futuro, sino aquí y ahora (The illusion of the end). Solo nos ilusiona el fin.

Lo que hace la actualidad es actualizar el fin. Pero con sus efectos, como el derivado del vaciado de la memoria histórica -con sentido- articulado con la catatonía universal alimentada por el flujo continuo de la actualidad. Cuanto más almacenamos en la memoria, menos memoria tenemos. Con todo el depósito de registros que ha posibilitado la digitalización, no tenemos ni memoria, ni olvido (The illusion of the end).

El diagnóstico que se deriva del dominio de la economía política del signo es el de una sociedad en la que todo circula, fluye, flota, supuestamente hasta el infinito. También los hombres y mujeres, debajo de sus signos en forma de CVs. En este tipo de economía, la explotación no está en el trabajo o la fábrica, está en nuestros signos, constantemente devaluados para la mayoría, y, a la vez, generando valor en su transformación como datos. Desde el signo, no hay alienación. No hay diferencia o separación de nosotros mismos. Somos convertidos en datos, sin corte alguno, sin solución de continuidad.

¿Dónde está el núcleo de algo parecido a un sistema político? Está en el propio atractivo del vacío. Irresistible (The illusion of the end) como el vértigo. Este es su diagnóstico de la cultura occidental, tomado de Jarry: hombres muertos pedaleando por inercia, infectados del virus de la servidumbre voluntaria (de La 
Boétie) a través de una televisión mcluhiana que nos ha hecho: indiferentes, distantes, escépticos e incondicionalmente apáticos (The illusion of the end).

Por esta atracción por el vacío, necesitamos alimentarnos de catástrofes. Son nuestro afrodisíaco (The illusion of the end). Pero, como pasa con los antibióticos, cada vez nos hacen menos efecto. Desde Hiroshima, pasamos de una catástrofe a otra; de una crisis, a otra; como de una cadena de televisión, a otra.

Tras establecernos en la inestabilidad del abismo, fijados en la incertidumbre, esta narración borgiana sobre el incierto Baudrillard termina con la recomendación de éste: no hay nada qué hacer sino sentarse y gozar del espectáculo. Es la incómoda comodidad de una sociedad que ha abandonado la historia.

La segunda narración de Borges en la que Baudrillard vuelve a aparecer es más breve y tiene ese perfil de texto inconcluso, abierto, que parece más un refinado elenco de pequeñas y, a la vez, prolijas descripciones. Es una detallada crónica del ... parece que Baudrillard estuviera escribiendo el guión del mundo. Su título también lo conocen ustedes: $A$ la búsqueda del clon perdido de Baudrillard. Su argumento vertebral puede calificarse de simple y responde al potencial de la patafísica aplicada de Baudrillard para apuntar la acumulación de simulacros que vivimos, tales como: un personaje de televisión y su familia llegan a la presidencia del país más poderoso del mundo, un periodista que nunca ha ejercido de periodista saca a Gran Bretaña de la Unión Europea y un largo etcétera.

Tal vez, Cataluña es el que aquí vivimos más cerca. Declaración en clave de simulacro de la independencia. Un simulacro de declaración que, en esa relación asintótica con la realidad, duró apenas unos segundos. Puigdemont sabía que era un simulacro, Junqueras sabía que era un simulacro, los mossos sabían que era un simulacro. La policía sabía que era un simulacro. Rajoy, nuestro gran cínico de la política, sabía que era un simulacro. Así lo declararon los acusados en el juicio. La gente que se manifestaba sabía que era un simulacro. Bueno, tal vez algunos se lo creyeron, como se lo creyeron los jueces del juicio del Procés, como se lo creyó la CUP y algún otro ¡Cómo se puede creer en un actor político que se lo cree!

El problema de los simulacros es que tienen consecuencias. $\mathrm{Y}$ es que: "las consecuencias de lo que no ha tenido lugar pueden ser tan graves como las de un acontecimiento histórico" (La guerra del Golfo no ha tenido lugar, p. 78). Que los jueces no crean que fuese un simulacro, es un problema. Pero jestaba tan bien hecho, que seguro que, si algún día llega esa declaración de independencia, se 
parecerá al doble que le antecedió! ¡El acontecimiento se parecerá a la representación del acontecimiento y, entonces, diremos: la independencia no ha tenido lugar! Y este es el núcleo del cuento borgiano, la necesidad de un simulacro de Baudrillard que esté ahí para contar lo que no tiene cuento.

Se aclama al autor por vislumbrar en la virtualidad de su presente lo que hoy es nuestro presente. Por ejemplo, con respecto a los populismos, su juego y retórica de la transparencia: no hay ocultación, los mensajes del populismo son transparentes (La Transparencia del Mal)... De hecho, es así que realzan el discurso de "lo auténtico". De hecho, lo malo es precisamente su transparencia ("el mal es la propia transparencia", nos dice Baudrillard). Lo que asusta no es lo que ocultan o pudieran ocultar. Lo que asusta es lo que dicen. Sus mensajes, no buscan "engañar" a sus receptores, sino su implicación, permitiendo la acelerada circulación de sus mensajes en las redes sociales. La lógica de sus mensajes no es la de verdad/mentira... Se dice lo que se quiere escuchar. Esto se soporta en algunos medios, a través de algunos canales que certifican el discurso (independientemente de "su verdad").

En esta segunda entrega, el autor argentino llama a un Baudrillard que tendría que estar eufórico, pletórico, intentando desentrañar esa sociedad que cubre la ausencia de ilusión con la ilusión de la ausencia de realidad condensada en las expectativas de los algoritmos, que constituyen la mayor condensación de ausencias de lo real que el hombre haya podido crear hasta el momento. Aunque los momentos históricos duran muy poco. Este es nuestro mundo. Este es nuestro no mundo, en el que los algoritmos predican nuestra voluntad; pero, cabe preguntarse ¿qué voluntad es ésta? Se trata de vestigios producidos, acumulan supuestas huellas, que adquieren objetividad no tanto en lo que son, sino en lo que hacen, en sus consecuencias. Cuando somos pasados por los algoritmos, nos performan, nos hacen actuar desde la instrucción algorítmica. Como el soldado Svejk, cumpliremos sus instrucciones, pues es la única manera que tendremos de sobrevivir.

Nuestra voluntad es ahora un algoritmo formalizado por no se sabe quién: ¿los desarrolladores de Netflix?, ¿los ingenieros de Google o Facebook? ¡Hay que descubrirse ante ellos! ¡Son capaces de inyectar coherencia en nuestras incoherentes vidas! Eso sí, una coherencia tan efímera como la que va a la próxima decisión de consumo que, a su vez, se convierte en huella para esa coherencia ¡Son ellos los que realmente nos han redescubierto como seres coherentes! 
Máquinas que nos imponen de "viva voz" normas de comportamiento. Ya casi no sabemos vivir sin Siri. El problema no es que la IA no sea inteligente sino que es más inteligente que la IN (inteligencia natural). Siempre llega antes y, así, en su capacidad de adaptación de la IN, ésta se ha hecho cómoda. Otra vez el doble somete al imposible original. Sociedad en la que hemos vendido nuestra inteligencia natural a Siri.

Esto es el gran espectáculo de la exterminación de lo real. Así, volviendo a utilizar las palabras de nuestro personaje en otro de sus encendidos discursos: "El crimen perfecto es el de una realización incondicional del mundo mediante la actualización de todos los datos, mediante la transformación de todos nuestros actos, de todos los acontecimientos en información pura; en suma: la solución final, la solución anticipada del mundo por clonación de la realidad exterminación de lo real en manos de su doble" (Crimen perfecto, p.41).

Nuestro Borges utiliza este segundo relato para reivindicar el potencial profético que dejó la obra de Baudrillard. Si en muchas narraciones de Borges está presente la Biblia, puede decirse que aquí también lo está. Y lo está en la forma de anuncio apocalíptico. En especial, esa forma de repetirnos que nuestra cultura es la del abismo. No es que esté ante el abismo sino que es del abismo.

Un ejemplo. Existe la ilusión de que el cambio climático es algo material, un esfuerzo de positivización, de indicadores -desde el número de huracanes, a los días de intensas lluvias o de olas de calor- que nos sitúan ante el abismo. Se nos dice, las leyes de la física no entienden de negaciones, denegaciones, esperas o de lenguaje político. Pero no solamente es tal materialidad la que nos sitúa ante el abismo, sino que somos nosotros mismos los que buscamos ese abismo. Se busca ese abismo que nos sitúa ante el vacío del espejo de la sociedad. Ante el mismo, tal vez nos preguntamos ¿dónde está lo social?, ¿dónde está la sociedad?, ¿dónde está la política? Casi, ni nos lo preguntamos.

Otro ejemplo. En el síndrome simbólico del efecto 2000 se escenificó un apocalipsis dirigido por virus informáticos. Pero ha sido un virus coronado (coronavirus) el que ha secuestrado a las tecnológicas. El modelo de infección con que nos habían asustado se vuelve ahora contra ellas. Contra nosotros. Y es que lo peor del coronavirus es que se comporta como se comportan los virus informáticos, permaneciendo en nuestros softwares sociales en silencio hasta que cualquier acontecimiento hace que se dispare. Paradójicamente, el patafísico coronavirus pone en su lugar a las tecnológicas, que es un no-lugar, pues ¿qué sentido tiene que los arquitectos e ingenieros de la infraestructura virtual, de la creación de los siempre distantes mundos en la nube digital, se encuentren cara a 
cara en algo como el Mobile? Un Mobile que se ha mostrado francamente inamovible.

Las armas de infección masiva no son los virus informáticos, inoculados desde un oscuro lugar de los sótanos del Kremlin, sino que son las representaciones mediáticas -y en las redes sociales- de los virus-virus. Incluso, cuando ocurre un hackeo más o menos general con inoculación de virus informáticos, lo peor es la epidemia de miedo que recorre Occidente, amenazando las cotizaciones en los corros de las bolsas de valores.

Dos signos más para entender -à la Baudrillard- lo sucedido con el no suceso del Mobile. Las empresas que empezaron a darse de baja en cadena fueron norteamericanas, europeas; sin embargo, eran muy pocas y pequeñas las empresas chinas que se pronunciaron en contra de su asistencia. Otro signo para la interpretación, que la gran empresa de los antivirus, Mcafee, se diera por vencida ante la amenaza del coronavirus.

La desaparición de lo real-social ha sido capaz de engullirse a los propios medios de comunicación tradicionales. La televisión, los periódicos, las radios han sido condenados al mismo destino (Crimen perfecto, p. 17): a desaparecer. Han sido sustituidos por fake news, que, por su credibilidad, circulan en todos los lados menos en ellos, terminando por circular en los propios medios tradicionales de comunicación. Reciben devuelta su propia imagen. Vomitan lo que otros vomitan y, así, el criterio de verdad ha sido sustituido por el principio de credibilidad (La ilusión... p.52). En medio, una cruzada estereofonía de noticias, en las que nada es verdad. Como dice Borges, con su habitual erudición, esto lo anuncian Canetti, Moya y el propio Baudrillard. Erudición sobre las múltiples voces de la estereofonía. Metaestereofonía que ensordece; pero ya es imposible regresar al sonido pre-estéreo de la música en mono (Ilusión... p.6).

Cuando Borges relata la fuerza de la razón que invade a los que buscan el clon de Baudrillard, se fundamenta en afirmaciones que hizo éste que hoy se muestran como certeros pronósticos. Cuando apuntó, hace más de cuarenta años, que: "Se ha buscado el secreto de la manipulación en una semiología implacable de los mass media. Pero se ha olvidado, en esta lógica naíf de la comunicación, que las masas son un médium más fuerte que todos los media, que son ellas quienes los envuelven y los absorben" ( $A$ l'ombre... p.48). 
Unos pronósticos que apuntan a que, otro de ellos, la clonación universal, parezca posible $\mathrm{y}$, así, el generalizado periplo hacia la inmortalidad, que es siempre el más terrible de los posibles destinos (La ilusión vital). Una sociedad en la que morir es un lujo. Más para un personaje, como el propio Baudrillard.

Ante tal estado de incertidumbre y desesperanza ¿qué nos queda? Precisamente eso, el estado de incertidumbre. Vuelvo a las palabras de tal particular personaje: "La incertidumbre se ha filtrado en todos los terrenos de la vida -no hay razón para que fuera privilegio exclusivo de la ciencia-. Y esto no es función de la complejidad de los parámetros, que pueden ser resueltos. Se trata de una incertidumbre radical porque está vinculado al carácter extremo de los fenómenos, y no sólo a su complejidad. Más allá del límite (ex - terminis), las propias leyes de la física se hacen reversibles, y ya no dominamos la regla del juego, si es que existe. De todos modos, ya no es la del sujeto y de la verdad" (Crimen perfecto, p. 82).

Borges es escéptico con la posición político-cínica-paroxística de Baudrillard; pero no hay muestras de otra. Una posición extraña que dice que: "Para pensar fenómenos extremos, tiene que convertirse él mismo en fenómeno extremo, abandonar cualquier pretensión crítica, cualquier ilusión dialéctica, cualquier esperanza racional, y entrar a su vez, a imagen y semejanza del mundo, en una fase paradójica, en una fase irónica y paraxística" (Crimen perfecto, p. 93). Pero hay que decir que Borges es escéptico con todo. Siempre moderado. Siempre moderadamente escéptico. De aquí que su personaje, Baudrillard, también sea finalmente escéptico: "tengamos por lo menos la inteligencia escéptica" ( $L a$ guerra no ha tenido lugar), nos dice.

Y en este punto llegamos a la reflexión final llena de preguntas ¿hasta qué punto Borges es el autor de Baudrillard? Parece claro que Baudrillard no es el autor de Borges. Pero si estamos en una sociedad en la que el doble, el simulacro, precede al acontecimiento, de manera que éste queda configurado por aquél... podría decirse también que Baudrillard es el autor de Borges y que la teoría política del primero está en el segundo. Lo real-social es una ficción.

FINAL: Como dice el propio Baudrillard, ningún crimen es perfecto. Tampoco el de la realidad de lo social. Menos aún, el crimen que aquí se acaba de cometer de la obra de Baudrillard, tomando seguramente el nombre de Borges en vano. Espero sepan perdonarme el pequeño juego. Nos dice el francés: "no se ha encontrado el cadáver de lo real' (Crimen perfecto, p.9). Solo ruego no lo sustituyan por el mío. Muchas gracias por haberse dejado llevar por esta ficción que, como bien saben, no ha tenido lugar. 
Javier Callejo Gallego (Madrid, 1960) es doctor en Sociología y licenciado en Sociología, Ciencias de la Información y Derecho por la Universidad Complutense de Madrid. Tras su experiencia como investigador social de mercados, especialmente en la empresa CIMOP, se dedica a la docencia. Ha publicado más de cien artículos en revistas científicas y capítulos de libros. Actualmente es catedrático de Sociología en la UNED. Sus líneas de investigación se establecen entre la Metodología y la Sociología de la Comunicación, junto con la Sociología del Tiempo y la Sociología del Consumo. Es en el curso de Praxis de Sociología del Consumo (UCM), en cuyo seno imparte docencia durante 20 años, donde se introduce más plenamente en la obra de Jean Baudrillard. mcallejo@poli.uned.es 